\title{
The Synergistic Effects of Lipoic Acid and Vitamin B in Sarcopenia
}

\author{
(1) Tahir Belice1, (1) Ümmügülsüm Keskin11, (1) İsmail Demir11, (1) Arif Yüksel1', (1) Selahattin Fehmi Akçiçek² \\ 1 University of Health Sciences Turkey, Izmir BozyakaTraining and Research Hospital, Internal Medicine Department, Izmir, Turkey \\ 2Ege University Faculty of Medicine, Department of Internal Medicine, Division of Geriatrics, İzmir, Turkey
}

\section{To the editor,}

There is a need for a proactive and holistic approach and a common mind to solve the problems of increasing of geriatric population both in number and ratio because of various reasons such as the emergence of geriatric syndromes as a result of multiple diseases and multiple risk factors. The causes of sarcopenia are not completely known due to diagnostic problems which are mostly originated from the complexity of atypical symptoms and the identification of etiopathogenesis with different mechanisms and; therefore, there is no definitive treatment of sarcopenia (1). The etiopathogenesis of sarcopenia in older patients includes chronic inflammation and impaired oxidant-anti-oxidant balance, neurological diseases, etc (2). Sarcopenia can be defined as a geriatric syndrome that leads to negative health outcomes such as decreased quality of life, limited daily activities, increased mortality rates and increased need for institutions such as geriatric care centres due to the loss of muscle mass and functions (3).

There has been a transition from a plant-based nutritional model that was rich in terms of micronutrients to a high-calorie model that lacks fibres and micronutrients (4). Similarly, during the transformation of our social structure from a pre-agricultural society to the formation of a modern society resulted in lifestyle-related metabolic diseases such as obesity and diabetes mellitus as well as neurological diseases such as cardiovascular diseases and dementia $(4,5)$. Particularly, the contribution of vitamins $B 6$ and $B 12$, which play a role in methionine cycle, for homocysteine recycling that is an independent risk factor in cardiovascular and neurological diseases shows the significance of dietary factors in the prevention and treatment of diseases $(6,7)$. Lee et al. (8) reported a statistically significant positive correlation between sarcopenia and homocysteine which is an inflammatory marker related to vascular aging. Lipoic acid is used in the treatment of diabetes and neurodegenerative diseases due to its protective and therapeutic effects such as chelating with metals in addition to free radical trapping, increasing the effectiveness of various other antioxidants, repairing oxidative damage and showing positive effects on insulin signalling pathways (9).

With the introduction of both vitamin B complexes and $\alpha$-lipoic acid together for the planned treatments of older patients at a risk of sarcopenia, we will be able to prevent the social and economic vulnerability of the older people to some extent (3). We did not find any studies that investigated the efficacy of both $\alpha$-lipoic acid and vitamin B complexes together in the prevention and treatment of sarcopenia. Therefore, we want to emphasise the need for further studies to show that both the anti-inflammatory and anti-oxidant effects of $\alpha$-lipoic acid and the neuroprotective and homocysteine-lowering effects of vitamin B6 and B12 treatments all together can be used in older patients for primary and secondary protection of sarcopenia $(8,10)$.

Keywords: Sarcopenia, thioctic acid, vitamin B complex

\section{Ethics}

Peer-review: Internally peer-reviewed.

\section{Author Contributions}

All authors contributed to the writing, reviewing and editing of this letter.

Conflict of Interest: The authors have no conflicts of interest to report.

Address for Correspondence: Tahir Belice, University of Health Sciences Turkey, İzmir Bozyaka Training and Research Hospital, Internal Medicine Department, İzmir, Turkey

Phone: +90 5062817530 E-mail: tahirbelice@gmail.com ORCID: orcid.org/0000-0001-7957-3423

Received: 19 Feb, 2020 Accepted: 03 Mar, 2020

Cite this article as: Belice T, Keskin Ü, Demir I, Yüksel A, Akçiçek SF. Lipoic Acid and Vitamin B in Sarcopenia. Eur J Geriatr Gerontol 2020;2(3):90-91

๑Copyright 2020 by the Academic Geriatrics Society / European Journal of Geriatrics and Gerontology published by Galenos Publishing House. 
Financial Disclosure: The authors declared that this study received no financial support.

\section{References}

1. Cruz-Jentoft AJ, Landi $F$, Topinková E. Understanding sarcopenia as a geriatric syndrome. Curr Opin Clin Nutr Metab Care 2010;13:1-7.

2. Larsson L, Degens $H$, Li M, Salviati L, Lee $Y$ I, Thompson $W$, Sandri M. Sarcopenia: Aging-related loss of muscle mass and function. Physiol Rev 2019;99:427-511.

3. Hirani V, Blyth F, Naganathan V, Le Couteur DG, Seibel MJ, Waite LM, Handelsman DJ, Cumming RG. Sarcopenia is associated with incident disability, institutionalization, and mortality in community-dwelling older men: the Concord Health and Ageing in Men Project. J Am Med Dir Assoc 2015;16:607-613.

4. Cordain L, Eaton SB, Sebastian A. Origins and evolution of the western diet: Health implications for the 21st century. Am J Clin Nutr 2005;81:341-354.
5. Milton K. Back to basics: Why foods of wild primates have relevance for modern human health. Nutrition 2000;16:480-483.

6. Collaboration HS. Homocysteine and risk of ischemic heart disease and stroke: A metaanalysis. JAMA 2002;288:2015-2022.

7. Seshadri S, Beiser A, Selhub J, Jacques PF, Rosenberg IH, D'Agostino RB, Wilson PW, Wolf PA. Plasma homocysteine as a risk factor for dementia and Alzheimer's disease. N Engl J Med 2002;346:476-483.

8. Lee WJ, Peng LN, Loh CH. Sex-different associations between serum homocysteine, high-sensitivity C-reactive protein and sarcopenia: Results from I-Lan longitudinal aging study. Exp Gerontol 2020;132:110832.

9. Moini H, Packer L, Saris NE. Antioxidant and prooxidant activities of alphalipoic acid and dihydrolipoic acid. Toxicol Appl Pharmacol 2002;182:84-90.

10. Landi F, Onder G, Bernabei R. Sarcopenia and diabetes: two sides of the same coin. J Am Med Dir Assoc 2013;14:540-541. 